\title{
DESIGN CRITERIA AND LOCATION OF SNOW FENCES
}

by

\section{HARALD NOREM}

Norwegian Geotechnical Institute, P.O. Box 40 - Tảsen, N-0801 Oslo 8, Norway

\section{ABSTRACT}

The paper describes experience gained in Norway regarding the design criteria and use in practice of snow fences. The paper is based on theoretical studies on drifting snow, model experiments and experience accumulated through practical consulting work.

Snow fence design is a compromise between the storage capacity and minimization of dimensioning forces. Design considerations include fence height $\mathrm{H}$, total snow fence density, and the gap between ground and fence. A gap of $0.15 \mathrm{H}-0.2 \mathrm{H}$ and a total density of $45 \%$ are usually recommended. On ridge crests the gap can be reduced to $0.1 \mathrm{H}$ and in areas where snow depths exceed $2.0 \mathrm{~m}$, it can be increased to $0.3 \mathrm{H}$. In such cases the fence density should be varied such that the total density, including the gap, will remain near $45 \%$. The height of the snow fences should be kept within 3.5 $4.5 \mathrm{~m}$ and the snow fences should be erected on the windward side of obstacles that create snowdrifts. The minimum distance from fence to road should not be less than $15 \mathrm{H}$; in certain circumstances in coastal climate, this can be reduced to $10 \mathrm{H}$.

\section{INTRODUCTION}

Snow fences have been used extensively in Norway and other northern countries for the last 100 years. They are erected on the windward side of the areas to be protected, to change the wind and snow accumulation conditions. Mostly, snow fences are used to:

- Reduce the quantity of drifting snow in populated areas, around buildings, and on roads and railways. On roads they will also increase visibility during snowstorms.

- Reduce the frequency of snow avalanches by collecting drifting snow on the windward side of the terrain exposed to avalanches.

\section{THE USE OF SNOW FENCES FOR ROADS}

Snow fences are used only where a road has an unfavourable location or improper design, such that the drifting snow accumulates on it, and are just one of several methods used to reduce the snow problems. Most of ten, road relocation, road raising on a fill, or cut section redesign, may be more costeffective. Where snow fences have been found optimal, their design and location have to be based upon the following assumptions:

1. Reduction of the wind velocity on the leeward side of the fence should be sufficient to collect the essential part of the drifting snow.

2. The area of the leeward side should be large enough to store the necessary quantity of drifting snow.

3. The size of the snow drift on the windward side of the fence should be minimized so that the fence will remain effective throughout the winter.

4. The snow fence should be effective for the prevailing wind direction, and wind from other directions should not accumulate snow close to the fence.

5. The snow fence should be cost-effective, with respect to both construction and maintenance.

\section{THE DESIGN OF SNOW FENCES}

Design is always a compromise between storage capacity and minimizing the dimensioning forces to make the fences most cost-effective. In general, previous investigations have been mostly concerned about storage capacity. However, all recent experiments conclude that optimum storage capacity does not exist per se. In practice, the design of snow fences can be varied within certain limits to take into account differences in climate and topography.

The effectiveness of a snow fence (Figure 1) depends mainly on:

$\mathrm{H}$ - The height of the fence

$s$ - The gap between fence and ground

d - The width of each slat

$\mathrm{P}=\frac{\Sigma \mathrm{d}}{\mathrm{H}-\mathrm{s}}$ The snow fence density (area of slats divided

$P_{0}=\frac{\Sigma d}{H}$ The total snow fence density (area of slats divided by the fence area including the gap between the fence and the ground.

\section{Height of the fence}

The required height of a snow fence depends on the quantity of drifting snow, the topography around the fences, and depth of snow on the ground. In Norway, where average depths most of ten vary between $1.0 \mathrm{~m}$ and $2.0 \mathrm{~m}$ in the mountains, snow fences between $3.5 \mathrm{~m}$ and $4.5 \mathrm{~m}$ high are most of ten used. In general, a fence higher than 4.5 does not seem to be cost-effective. Where high fences are needed, two or more rows of lower fences will probably prove more efficient.

The density of the fences

The existing literature concludes that a snow fence density of around $50 \%$ has the highest storage capacity. Curves of storage capacity versus snow fence density are however fairly flat between $45 \%$ and $55 \%$.

Both wind and sedimentation model experiments were carried out at the River and Harbour Laboratory in Trondheim in 1969. The model scale was 1: 5, and

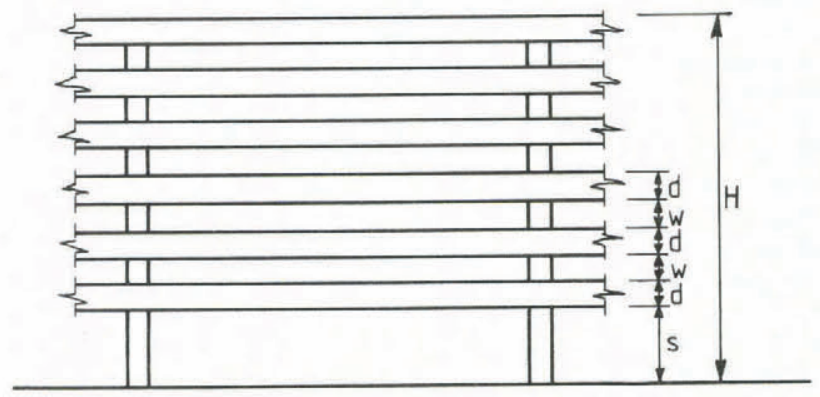

$d=$ Width of the horizontal slats.

$w=$ Space between the horizontal slats.

$s=$ Space between the ground and the fence.

$\mathrm{H}=$ Total snow fence height.

Fig.1. Definition of characteristic parameters. 
TABLE 1. DATE RELATING TO THE FENCES TESTED BY THE RIVER AND HARBOUR LABORATORY, TRONDHEIM.

\begin{tabular}{ccccc}
\hline $\begin{array}{l}\text { Fence } \\
\text { height } \\
\mathrm{H}(\mathrm{cm})\end{array}$ & Gap & $\begin{array}{c}\text { Rel. gap } \\
\mathrm{s}(\mathrm{cm})\end{array}$ & $\begin{array}{c}\text { Fence } \\
\text { density } \\
\mathrm{P}(\%)\end{array}$ & $\begin{array}{c}\text { Total } \\
\text { density } \\
\mathrm{P}(\%)\end{array}$ \\
\hline 43.8 & 9.0 & 0.21 & 69 & 55 \\
43.8 & 9.0 & 0.21 & 55 & 44 \\
43.8 & 9.0 & 0.21 & 41 & 33 \\
53.8 & 9.0 & 0.17 & 54 & 45 \\
53.8 & 19.0 & 0.35 & 55 & 36 \\
51.4 & 16.6 & 0.32 & 69 & 47 \\
43.8 & 1.5 & 0.03 & 68 & 66 \\
\hline
\end{tabular}

styrofoam particles were used as model snow (Tesaker 1970). In contrast to other experiments, both density and gap between the ground and the fences were varied over a wide range, respectively $41-69 \%$ and $0.03 \mathrm{H}-0.35 \mathrm{H}$ (see Table 2).

Figure 2 shows the relationship between maximum wind velocity, recorded $0-0.4 \mathrm{H}$ above the ground, and distance from the fences. At a distance of $5 \mathrm{H}$ the lee effect, and probably the storage capacity, is better related to $\mathrm{P}_{0}$ than to $\mathrm{P}$. A similar conclusion was also obtained from experiments with model snow, that gave the best capacity for fences with total density of $45-50 \%$ and a gap of $0.15-0.18 \mathrm{H}$. Storage capacity is reduced by less than $20 \%$ with the gap varying between $0.1 \mathrm{H}$ and $0.22 \mathrm{H}$, and with $\mathrm{P}_{0} \approx 45 \%$. Dyunin and Komarow (1963) assumed that the relative wind velocity should be greater than $100 \%$ (it then has a strong eroding effect) beneath the fence, and at some distance from it, the reduction of the wind velocity should be at least $60 \%$. These assumptions are obtained for snow fences with a gap of $0.15-0.25 \mathrm{H}$ and a total density of about $45 \%$, which is recommended Norwegian practice.

The gap between the fence and the ground

The purpose of the gap under the snow fence is to create a strong, eroding wind close to the ground. This eliminates accumulation of snow close to the fence, which would reduce the effectiveness of the fence later in winter, and give high snow creeping forces on the fence during the melting season.

Previous investigators have been more concerned about fence density than the size of the gap. Finney

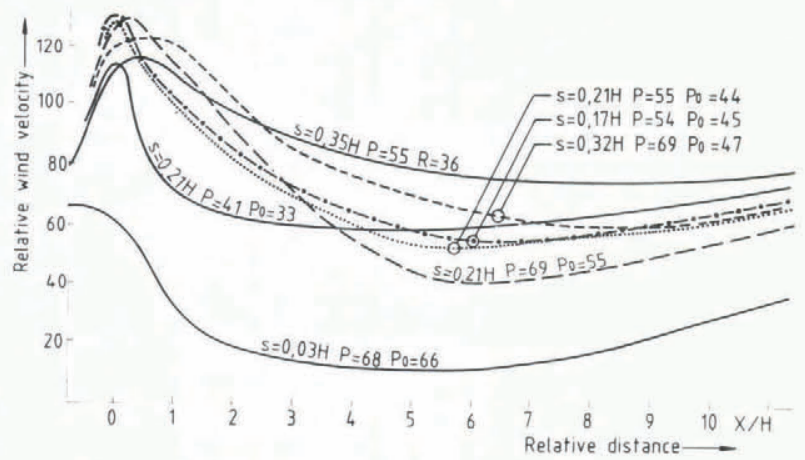

Fig.2. Results of the wind model tests. The maximum velocity, $0-0,4 \mathrm{H}$ above the ground, related to the distance from the fences.
(1934) concluded that $2.0 \mathrm{~m}$ high fences should have a gap of $0.3 \mathrm{~m}$, and Tabler (1980) recommends a gap of $0.1 \mathrm{H}$. Obviously, however the gap should depend on both the height of the fence and the snow depths nearby. In horizontal terrain where snow depths average $0.3-0.4 \mathrm{H}$, a gap of $0.15 \mathrm{H}-0.2 \mathrm{H}$ is most of ten used. On ridges and other terrain formations with less snow, a gap of $0.2 \mathrm{H}$ will be too high, because the eroding wind beneath the fence may be too strong and prevent the accumulation of snow drift. Gaps down to $0.1 \mathrm{H}$ are recommended in such cases.

In areas where the local snow depths exceed $2.0 \mathrm{~m}$, gaps of up to $0.3 \mathrm{H}$ have been used. The density of the fences has in these cases been increased to $65 \%$ to ensure a total fence density close to $45 \%$. In areas with large snow depths, the snow will accumulate around the fence and reduce the effective gap fairly early in the winter. Snow fences with an extra gap width will therefore be more effective later on in the season than ordinary fences. They will also be less exposed to snow creeping forces and are less likely to be filled up with snow from secondary wind directions.

\section{The width of the slats}

Most of the fences used in Norway are permanent constructions. Stiff materials including wood, steel and aluminium have been used. A Swiss experiment (Schneider 1959) concluded that fences with many narrow slats collected the snow closer to the snow fences than fences with wider slats. That is also confirmed by the Norwegian experience. Today, slat widths of at least $10 \mathrm{~cm}$ are recommended.

\section{TYPES OF SNOW FENCES}

Figures 3,4 and 5 show the three snow fence types most used today in Norway. All are of wood and designed for fairly large snow creeping forces compared to other fences referred to in the literature. The dimensions shown have been deemed necessary to withstand the snow creeping forces. The $3.5 \mathrm{~m}$ fence shown in Figure 3 is mostly used on roads at or just above the tree line where average snow depth varies between $1.0-1.5 \mathrm{~m}$. The number of days with strong

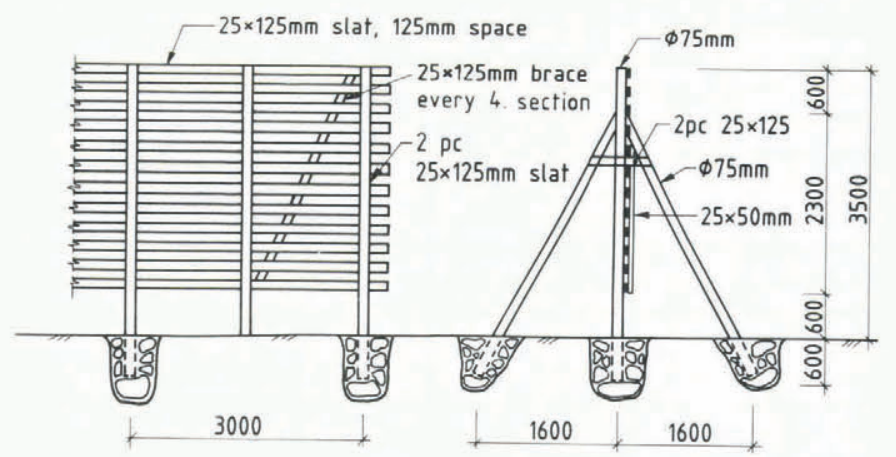

Fig.3. Snow fence, $3.5 \mathrm{~m}$.

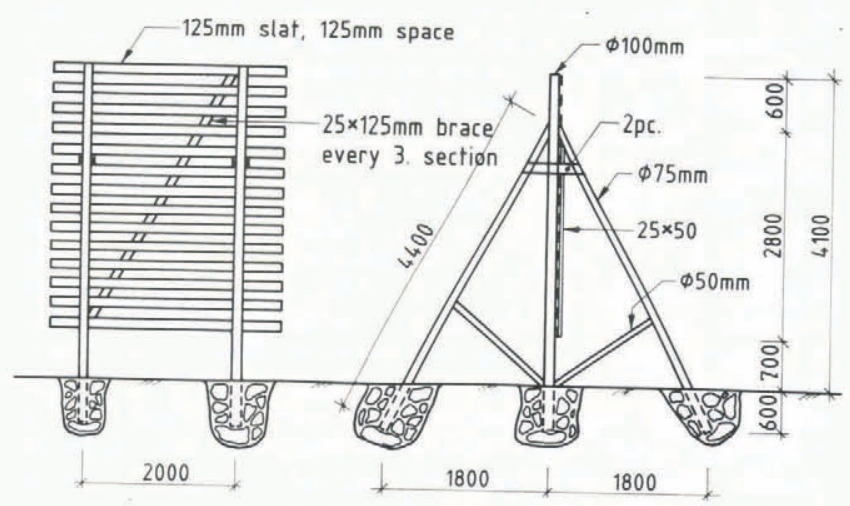

Fig.4. Snow fence, $4.1 \mathrm{~m}$. 


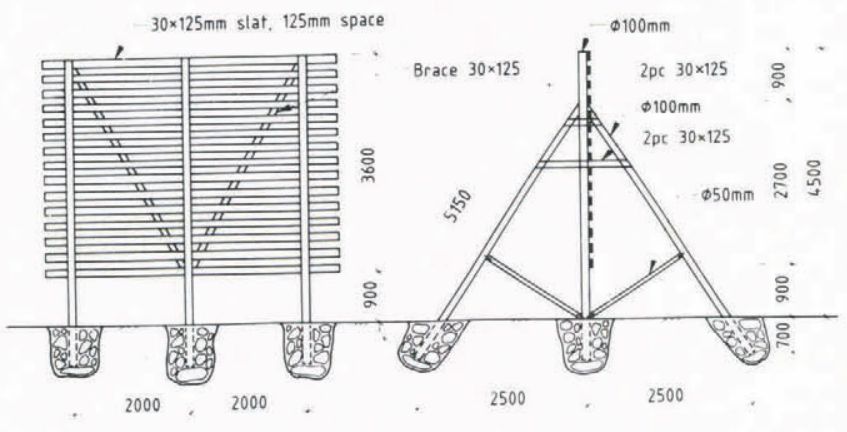

Fig.5. Snow fence, $4.5 \mathrm{~m}$.

winds ( $\geqslant 6$ Beaufort $=10.7 \mathrm{~m} / \mathrm{s}$ ) should not exceed 10-12 per winter month. In more severe climate with snow depths up to $2.0 \mathrm{~m}$ and 15 days with strong wind per winter month, the $4.1 \mathrm{~m}$ fence (Figure 4 ) is preferred. The $4.1 \mathrm{~m}$ fence will also be used in less exposed climatic zones where the terrain inclination is up to $10^{\circ}$. The $4.1 \mathrm{~m}$ fence may be extended to about $4.5 \mathrm{~m}$ where the snow seldom accumulates around the fence. The 4.5 $\mathrm{m}$ fence in Figure 5 can only be justified where experience has demonstrated that snow creeping forces are extremely high.

So far, only vertical snow fences have been used, though it is known that inclined fences provide better storage capacity. Hallberg (1943) found that fences with an inclination of $5^{\circ}$ had the best capacity, and Tabler (1974) recommended $15^{\circ}$ inclination. The reason for using vertical fences is partly conservatism and partly that inclined fences will be more exposed to snow creeping forces.

\section{LOCATION OF FENCES}

Experience has shown that not all terrain is suitable for the use of snow fences. When evaluating the terrain and the snow problems, one has to take into account: prevailing wind directions, quantity of snow and its distribution on the ground, and the inclination and shape of the terrain.

Snow fences are most effective when only one prevailing wind-direction forms snow drifts. In such cases, the fences have to be located normal to the wind direction. In the case of two or more prevailing wind directions with heavy snowdrifts, the snow behind the fence may work as a natural snow fence and accumulate snow around the fence. The storage efficiency of the fence will then be reduced for the rest of the winter. In these areas, snow fences should either be avoided or designed so that maximum snow accumulation occurs some distance away from the fence.

The use of snow fences is also improved when the angle between the road and the wind is close to $90^{\circ}$. With small angles, secondary wind directions will very of ten form snowdrifts on the road.

Snow fences have to be erected on the windward side of the terrain formations which are at the origin of the natural snowdrifts. On the leeward side of these formations, wind conditions are not favourable, as the terrain will probably accumulate snow around the fence. Therefore, the wind should be free of vortices at the location. Locations with strong eroding winds are preferred.

The extension of snowdrifts is reported to vary between $15 \mathrm{H}$ and $25 \mathrm{H}$. In areas with large snow depths a value of $15 \mathrm{H}$ seems to be most usual. The minimum distance between the fence and the road should therefore be $15 \mathrm{H}$ parallel to the wind direction. In areas of humid climate, where the snow problems only occur simulataneously with strong winds and snow precipitation, the distance may be reduced to a minimum, since the snowdrift content will increase rapidly behind the fence. A distance of $10 \mathrm{H}$ has been tried with some success. The height of the fences has in these cases been overestimated. Consequently the capacity and the length of the drift will never reach their maximum.

In more continental climates, the snow drift content will not increase so rapidly with increasing distance from the fence, and it is possible to find the optimal location in a wider area. The maximum distance between the fences and the road should be approximately $100 \mathrm{~m}$ for a $4.0 \mathrm{~m}$ fence parallel to the wind directions.

Where the wind blows uphill the lee area behind the fences, and consequently the storage capacity of the fences are reduced. In such terrain formations snowfences should be avoided. If it is necessary to use fences, the distance between the fences and the road should be reduced compared to the recommendations presented above.

Where the wind blows downhill, the snowdrifts can be much longer than $15 \mathrm{H}$, and the distance should be increased, as also clearly pointed out by Tabler (1974). In lee zones, where the wind blows downhill, the wind picks up less snow than in flatter terrain, and the distance between the fences and the road can for this reason be increased.

With the optimal locations for the snow fences, one starts the design of the fences. In our opinion, the fences should have a constant height and gap above the ground surface after the snow has smoothed out small roughnesses. The gap and density of the fences are then determined based upon assumptions of local snow depths and climate as described earlier in this paper.

\section{REFERENCES}

Finney E A 1934 Snow control on the highways. Michigan State College, Eng. Exp. Station Bulletin no 57

Duynin A, Komarow A A 1963 On the construction of snow fences. Technical Translation 1103, National Research Council of Canada, Ottawa

Hallberg S 1943 [Some investigations about snow fences.] Statens Veginstitut, Meddelande no 67, Stockholm (in Swedish)

Norem H 1975 Designing highways situated in areas of drifting snow. Research and Engineering Laboratory, Draft Translation 503, Hanover, New Hampshire

Norem H 1975 [Design and location of snow fences.] The Norwegian Road Research Laboratory, Meddelelse $\mathrm{nr}$ 49, Oslo (in Norwegian)

Schneider T R 1959 Schneeverwehungen und winterglatte. Interner Bericht des Eidgenössiches Institutes für Schnee Science und Lawinenforschung no 302, Davos

Tesaker 1970 [Snow fences, model experiments.] The River and Harbour Laboratory, NTH, Trondheim (in Norwegian, unpublished)

Tabler R D 1974 New engineering criteria for snow fence systems. Transportation Research Record 506, Washington DC

Tabler R D 1980 Geometry and density of drifts formed by snow fences. Journal of Glaciology 26(94): $402-420$ 